\title{
Mixed infections with Opisthorchis viverrini and intestinal flukes in residents of Vientiane Municipality and Saravane Province in Laos
}

\author{
J.-Y. Chai ${ }^{1 *}$, J.-H. Park ${ }^{1}$, E.-T. Han ${ }^{2}$, S.-M. Guk ${ }^{1}$, E.-H. Shin ${ }^{1}$, A. Lin ${ }^{1}$, \\ J.-L. Kim ${ }^{1}$, W.-M. Sohn ${ }^{3}$, T.-S. Yong ${ }^{4}$, K.S. Eom ${ }^{5}$, D.-Y. Min ${ }^{6}$, \\ E.-H. Hwang7 , B. Phommmasack ${ }^{8}$, B. Insisiengmay ${ }^{8}$ and H.-J. Rim ${ }^{9}$ \\ ${ }^{1}$ Department of Parasitology and Tropical Medicine, Seoul National \\ University College of Medicine, and Institute of Endemic Diseases, Seoul \\ National University Medical Research Center, Seoul 110-799, Korea: \\ ${ }^{2}$ Department of Parasitology, College of Medicine, Kangwon National \\ University, Chuncheon 200-701, Korea: ${ }^{3}$ Department of Parasitology and \\ Institute of Health Sciences, Gyeongsang National University College \\ of Medicine, Jinju 660-751, Korea: ${ }^{4}$ Department of Parasitology, College \\ of Medicine, Yonsei University, Seoul 120-752, Korea: ${ }^{5}$ Chungbuk National \\ University, Chongju 361-763, Korea: ${ }^{6}$ Hanyang University, Seoul 133-791, \\ Korea: ${ }^{7}$ Korea Association of Health Promotion, Seoul 157-704, Korea: \\ ${ }^{8}$ Department of Hygiene and Prevention, Ministry of Public Health, \\ Vientiane, Lao PDR: ${ }^{9}$ Department of Parasitology, Korea University, \\ Seoul 136-705, Korea
}

\begin{abstract}
Faecal examinations for helminth eggs were performed on 1869 people from two riverside localities, Vientiane Municipality and Saravane Province, along the Mekong River, Laos. To obtain adult flukes, 42 people positive for small trematode eggs (Opisthorchis viverrini, heterophyid, or lecithodendriid eggs) were treated with a $20-30 \mathrm{mg} \mathrm{kg}^{-1}$ single dose of praziquantel and purged. Diarrhoeic stools were then collected from 36 people (18 in each area) and searched for helminth parasites using stereomicroscopes. Faecal examinations revealed positive rates for small trematode eggs of $53.3 \%$ and $70.8 \%$ (average $65.2 \%$ ) in Vientiane and Saravane Province, respectively. Infections with $O$. viverrini and six species of intestinal flukes were found, namely, Haplorchis taichui, H. pumilio, H. yokogawai, Centrocestus caninus, Prosthodendrium molenkampi, and Phaneropsolus bonnei. The total number of flukes collected and the proportion of fluke species recovered were markedly different in the two localities; in Vientiane, 1041 O. viverrini (57.8 per person) and 615 others (34.2 per person), whereas in Saravane, 395 O. viverrini (21.9 per person) and 155207 others (8622.6 per person). Five people from Saravane harboured no O. viverrini but numerous heterophyid and/or lecithodendriid flukes. The results indicate that $O$. viverrini and several species of heterophyid and lecithodendriid flukes are endemic in these two riverside localities, and suggest that the intensity of
\end{abstract}


infection and the relative proportion of fluke species vary by locality along the Mekong River basin.

\section{Introduction}

Foodborne zoonotic parasites, including liver and intestinal flukes, are recognized as an important group of emerging and re-emerging human pathogens (WHO, 1995, 2004). In Southeast Asia, two species of liver flukes, Clonorchis sinensis and Opisthorchis viverrini, and more than 50 species of intestinal flukes, including Heterophyes nocens, Metagonimus yokogawai, Haplorchis spp., Centrocestus spp., Prosthodendrium molenkampi, Phaneropsolus bonnei and Echinostoma spp., are important representative examples of foodborne zoonotic parasites ( $\mathrm{Yu} \&$ Mott, 1994; Chai \& Lee, 2002; Chai et al., 2005).

Lao People's Democratic Republic (Lao PDR; Laos) is located in the middle of South Asia, and borders China, Myanmar, Thailand, Vietnam and Cambodia. The Mekong River runs from north to south in a southeasterly direction. As has been reported in northeast Thailand (Radomyos et al., 1994), foodborne zoonotic parasites are also prevalent in Laos. However, little information is available on the parasite species or the prevalence and intensity of parasitic infections. Previous studies have reported that Opisthorchis viverrini is the major foodborne parasite in the Vientiane Municipality (Sornmani et al., 1974; Pholsena et al., 1991), and in Khammouane (Kobayashi et al., 1996) and Champassak Provinces (Chai \& Hongvanthong, 1998). With regard to intestinal flukes, a small number of studies (Ditrich et al., 1990; Giboda et al., 1991) have associated Haplorchis taichui with human infections in Laos. However, no data are available on the prevalence and intensity of $H$. taichui infection or of other intestinal fluke species. Therefore, the present study was performed to determine the status of infection of $O$. viverrini, $H$. taichui, and other species of foodborne parasites among the residents of two different localities along the Mekong River basin.

\section{Materials and methods}

\section{Areas surveyed}

Four villages (Haikham, Nakhouai Tai, Nakhouai Kang, and Thanaleng) in Vientiane Municipality and three villages (Mouang, Saphad, and Bunkang) in Saravane Province are involved in this study (fig. 1). The former four villages are located near the Mekong River, whereas the latter three are located along a tributary (fig. 1). Most residents are agricultural workers, and some residents used to catch freshwater fish and aquatic insect larvae such as the naiads of dragonflies from small streams and ponds, and consume them raw or improperly cooked. Traditional dishes called 'Koi pla' (contains raw fish) and 'Som fak' (contains fermented fish) are popular food items in these villages, as they are in northeast Thailand (Rim, 1982).

\section{Faecal examinations}

A total of 1869 faecal samples, one sample from each person, were collected from residents (886 men and 983 women; aged 3-79 years), during November 2002 and November 2003. Samples were transported to a laboratory (a Malaria Station) in each locality within 2-3 days of collection and stored at $4^{\circ} \mathrm{C}$ until examined. The KatoKatz thick smear technique was used to detect helminth eggs. It was difficult to differentiate eggs of O. viverrini from those of heterophyids such as $H$. taichui and lecithodendriids like Prosthodendrium molenkampi and Phaneropsolus bonnei (Tesana et al., 1991; Kaewkes et al., 1991; Ditrich et al., 1992; Chai et al., 2005) and therefore, these eggs were recorded as small trematode eggs.

\section{Worm collection}

Worm collection and faecal examinations of villagers were approved by the Ministry of Public Health, Lao PDR, under the terms of the Korea-Laos agreement on Parasite Control in Lao PDR (1999-2004). A total of 42 people who harboured small trematode eggs (opisthorchiid or heterophyid/lecithodendriid eggs), 20-22 individuals from each area, were selected for adult fluke collection. These subjects, who all provided informed consent, visited field stations where they were treated

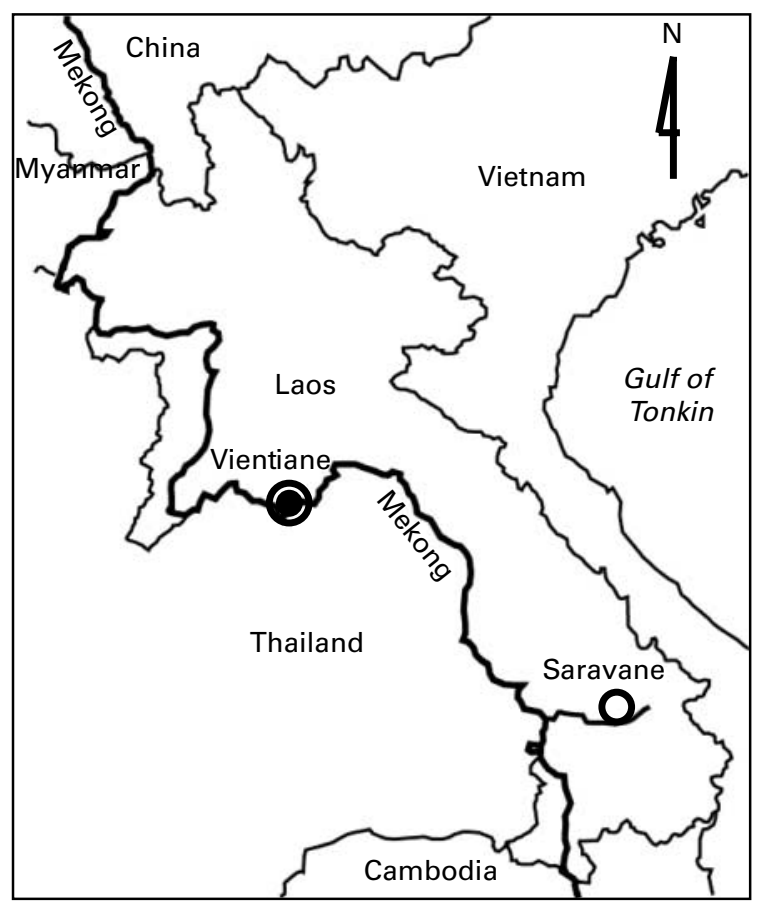

Fig. 1. Map showing the two surveyed localities $(\bigcirc)$ of Laos: Vientiane Municipality and Saravane Province. 
with a single dose $\left(20-30 \mathrm{mg} \mathrm{kg}^{-1}\right)$ of praziquantel (Shinpoong Pharmaceutical Co., Seoul, Korea) and were then magnesium salt purged. Whole diarrhoeic stools passed successively 4-5 times were collected and pooled. Stools were then washed several times with 10 volumes of water, sieved through a $2 \mathrm{~mm}$ mesh and re-suspended in water. After $10 \mathrm{~min}$, the upper clean layer was discarded, and the lower dark layer was fixed with $0.5-1.0 \%$ neutral buffered formalin and searched for worm parasites under a stereomicroscope. Some samples were also transported to the Department of Parasitology and Tropical Medicine, Seoul National University College of Medicine, Seoul, Korea for the same purpose. Worms were collected using a glass pipette and washed several times in water. The number of worms collected was counted, and some were fixed with $10 \%$ formalin under cover slip pressure, acetocarmine-stained, and morphologically identified under a light microscope.

\section{Statistical analysis}

Faecal examination results for trematode eggs were analysed with respect to subject age, sex, and place of residence using the student's $t$-test and the chi-square test.

\section{Results}

Egg positive rates

Overall helminth egg positive rates were significantly $(P<0.001)$ higher among residents of Saravane Province $(75.7 \%)$ than among those of Vientiane (57.3\%) (table 1). Small trematode eggs, including those of Opisthorchis viverrini, heterophyids and lecithodendriids, were the most frequently encountered, with an egg positive rate of $53.3 \%$ in Vientiane and $70.8 \%$ in Saravane (table 1). This difference between the two regions was statistically significant $(P<0.001)$. The eggs of other parasites included those of hookworms $(4.0 \%$ and $10.6 \%$, respectively), Trichuris trichiura (5.0\% and $1.5 \%)$, Taenia spp. $(1.8 \%$ and $5.7 \%)$, Ascaris lumbricoides $(0.5 \%$ and $2.5 \%)$, and echinostomes $(0.3 \%$ and $1.3 \%)$. Egg positive rates were not significantly $(P>0.01)$ different between men and women (data not shown), and the age-dependent prevalence was unremarkable after 20 years of age (data not shown).

\section{Worm collection results}

Worm collection was completed successfully in 36 persons (18 in each area; 22 men and 14 women; age range 10-67 years) (table 2). In addition to O. viverrini, six species of intestinal flukes were collected, including three species of Haplorchis (H. taichui, $H$. pumilio and H. yokogawai), and Centrocestus caninus, P. molenkampi and $P$. bonnei (table 2; figs. 2-6). The numbers of specimens of the fluke species collected were markedly different in the two areas (table 2). In the 18 subjects from Vientiane Municipality, 1041 O. viverrini specimens (3-315 individually; 57.8 per person) and 615 intestinal flukes (1-168 individually; 34.2 per person) were collected. Opisthorchis viverrini comprised $62.9 \%$ of flukes collected and intestinal flukes $37.1 \%$. In contrast, in 18 persons from Saravane Province, 395 O. viverrini (0-125 individually; 21.9 per person) and 155,207 intestinal flukes (135-37,200 individually; 8622.6 per person) were collected, where O. viverrini comprised only $0.3 \%$ of the total flukes. These differences in the patterns of flukes collected from the two localities were statistically significant $(P<0.001)$.

Of the intestinal flukes, $H$. taichui, a heterophyid species, was the dominant species, followed by H. yokogawai (in Vientiane) or H. pumilio (in Saravane), P. molenkampi, P. bonnei and C. caninus (table 2). The highest number of $H$. taichui collected from a single person was 36,658 (in Saravane), and the lowest 0 (in Vientiane), with an average number of collected worms per person of 26.9 in Vientiane and 8514.1 in Saravane, demonstrating more than 300 -fold higher worm burdens in the latter area. The number of $H$. pumilio collected per person ranged from 0 to 502 , with an average of 0.6 in Vientiane and 62.5 in Saravane, which was decidedly smaller than the number of $H$. taichui. The number of $H$. yokogawai ranged from 0 to 43 , with a mean of 3.6 in Vientiane and 1.2 in Saravane. Other heterophyid flukes collected included C. caninus (four specimens in Vientiane). With reference to lecithodendriid flukes, P. molenkampi was recovered in both localities, but

Table 1. Helminth egg positive rates in the faeces of villagers in Vientiane Municipality and Saravane Province, the Mekong River basin, Laos.

\begin{tabular}{lccr}
\hline & \multicolumn{3}{c}{ No. of egg positive cases (\%) by areas } \\
\cline { 2 - 4 } Helminth species & Vientiane & Saravane & Total \\
\hline No. examined* & 599 & 1270 & 1869 \\
No. helminth positive (\%) & $343(57.3)$ & $962(75.7)$ & $1305(69.8)$ \\
Ascaris lumbricoides & $3(0.5)$ & $32(2.5)$ & $35(1.9)$ \\
Hookworms & $24(4.0)$ & $135(10.6)$ & $159(8.5)$ \\
Trichuris trichiura & $30(5.0)$ & $19(1.5)$ & $49(2.6)$ \\
Opisthorchis viverrini and small trematode eggst & $319(53.3)$ & $899(70.8)$ & $1218(65.2)$ \\
Taenia spp. & $11(1.8)$ & $73(5.7)$ & $84(4.5)$ \\
Echinostomes & $2(0.3)$ & $16(1.3)$ & $18(1.0)$
\end{tabular}

* Faecal examination was performed by the Kato-Katz thick smear technique. One smear was examined for each person.

t Including the eggs of heterophyids (Heterophyidae) and lecithodendriids (Lecithodendriidae). 


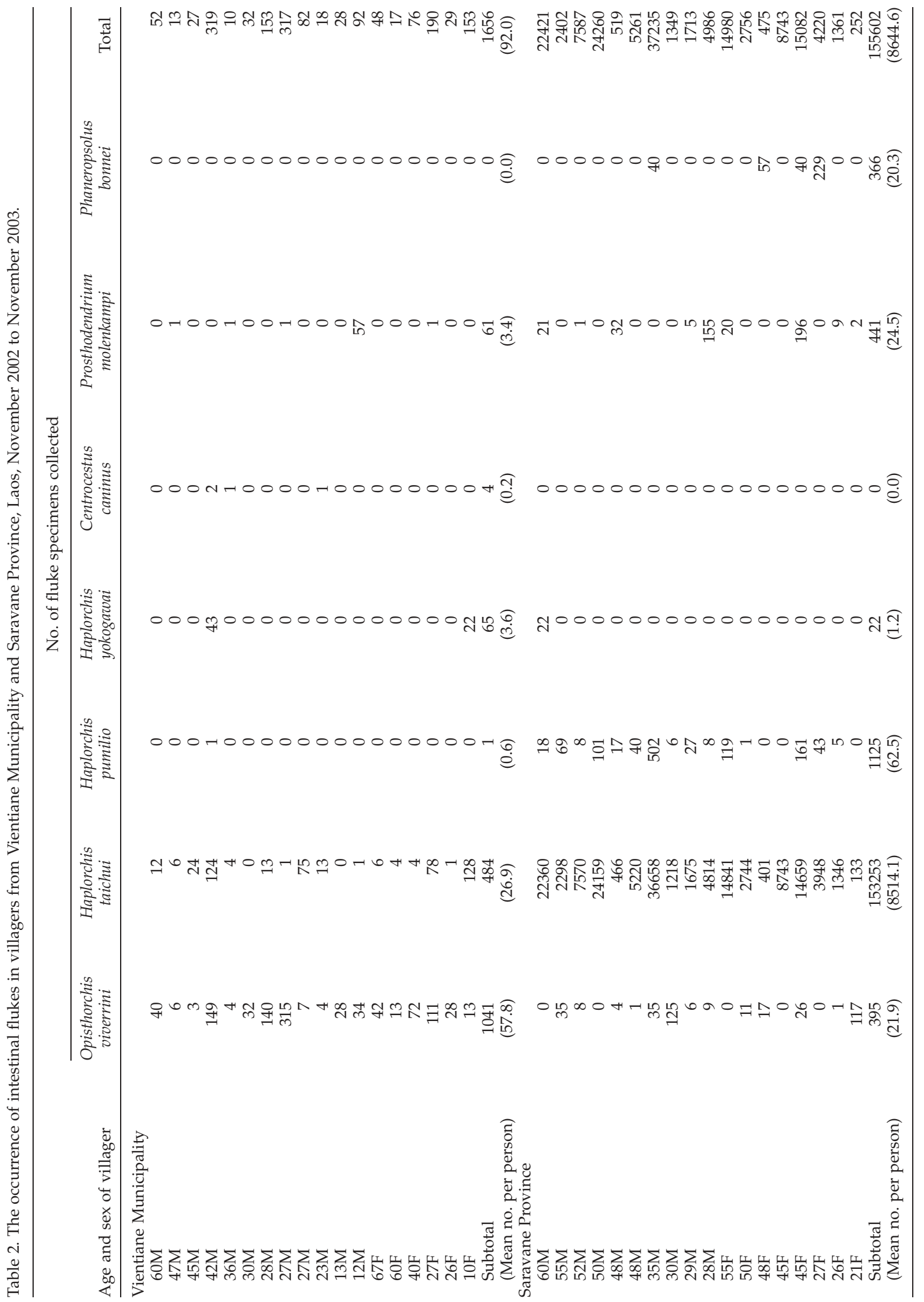



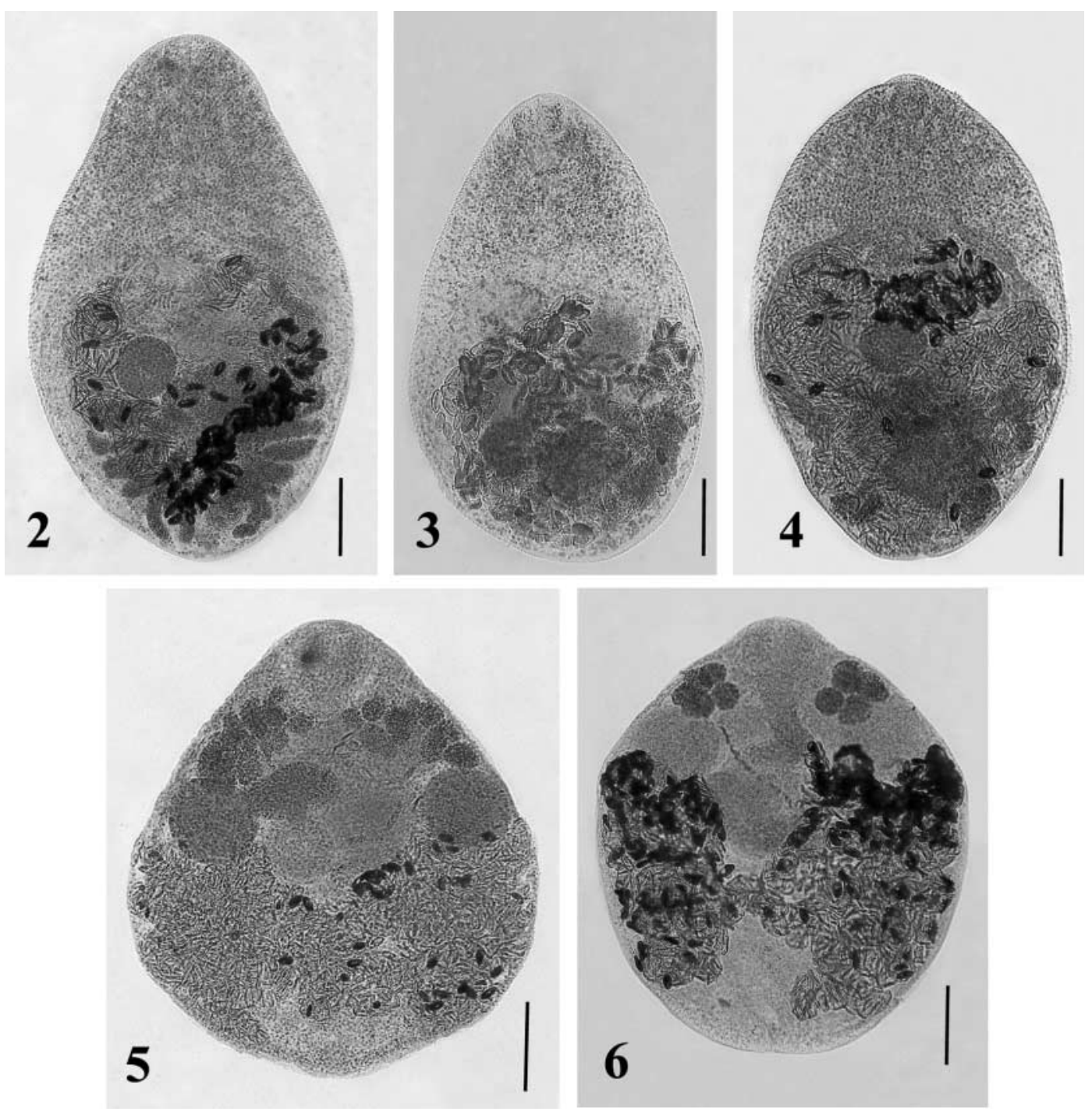

Figs. 2-6. Adult specimens of Haplorchis taichui (2), H. pumilio (3), H. yokogawai (4), P. molenkampi (5) and P. bonnei (6) recovered from the villagers of Saravane Province, Laos, after praziquantel treatment and purgation. Bars $=0.2 \mathrm{~mm}$.

P. bonnei was found only in Saravane residents (table 2). The number of $P$. molenkampi worms collected per person ranged from 0 to 57 in Vientiane (3.4 per person) and 0 to 196 in Saravane (24.5), and the number of P. bonnei ranged from 0 to 229 (20.3) in Saravane.

\section{Discussion}

The results of the present study are important from a parasitological and a public health point of view. Various species of intestinal flukes including $H$. taichui, H. pumilio, $H$. yokogawai, P. molenkampi and P. bonnei were found in mixed-infections with $O$. viverrini among the villagers of Vientiane Municipality and Saravane Province. Interestingly, the proportion of $O$. viverrini and intestinal flukes was markedly different in the two surveyed localities, i.e. O. viverrini composed two-thirds of all flukes recovered in Vientiane, whereas intestinal flukes accounted for over $99 \%$ of all recovered flukes in Saravane Province. Moreover, the recovery of adult worms of $H$. pumilio, $H$. yokogawai, P. molenkampi, $P$. bonnei and C. caninus are recorded for the first time in humans from Laos, whereas $H$. taichui from Laotians has been reported previously (Giboda et al., 1991).

Before the 1970s, only two species of liver flukes, namely $O$. viverrini and Fasciolopsis buski, were recorded among the list of Laotian trematodes infecting man (Segal et al., 1968). In the case of O. viverrini, high prevalences have been reported among residents in different localities of Laos (Sornmani et al., 1974; Giboda et al., 1991; Pholsena et al., 1991; Kobayashi et al., 1996, 2000; Chai \& Hongvanthong, 1998). A nationwide survey in 18 administrative districts also reported a high 
prevalence of opisthorchiasis among primary schoolchildren, particularly in middle and southern Laos, along the Mekong River (Rim et al., 2003).

Heterophyid flukes were first reported in Laos in 1990 when metacercariae of $H$. taichui, $H$. pumilio, Centrocestus formosanus and Stellantchasmus falcatus were discovered in fish caught in the Vientiane Municipality and in the Nam Ngum water reservoir (Scholtz et al., 1990), and adult flukes of $H$. taichui, $H$. pumilio, $H$. yokogawai and $S$. falcatus were recovered from the intestines of domestic cats (Ditrich et al., 1990). Subsequently, adult $H$. taichui flukes were identified in five Laotian students studying in Czechoslovakia (Giboda et al., 1991). In the present study, $H$. taichui was found to be the most common humaninfecting foodborne trematode in Saravane Province but it takes second place to $O$. viverrini in Vientiane Municipality. It was also surprising to find that 15 of 18 persons from Saravane were infected with more than 1000 specimens of $H$. taichui and that five were infected with more than 10,000 worms. The sources of Haplorchis spp. infection are known to be various species of freshwater or brackish water fish (Scholtz et al., 1990; Yu \& Mott, 1994; Chai et al., 2005). All the people infected with Haplorchis spp. in this study had eaten raw freshwater fish.

With reference to the lecithodendriid flukes, the presence of human $P$. molenkampi and $P$. bonnei infections was first reported after autopsying 24 people who resided in Udornthani and Nonkhai Provinces, Thailand (Manning et al., 1971). Later, high prevalences of these fluke infections were reported in Thailand (Radomyos et al., 1984, 1994). The prevalence values for P. molenkampi and P. bonnei were $19.4 \%$ and $15.0 \%$, respectively, among $681 \mathrm{egg}$ positive individuals (small trematode eggs including O. viverrini) treated with praziquantel and purged in northeast Thailand (Radomyos et al., 1994). As northeast Thailand is geographically close to Laos, and in particular, Nonkhai is near the border between the two countries, these two lecithodendriid flukes were presumed to be distributed in Laos although they had never been previously reported (Waikagul, 1991). Thus the present study proves their presence in Laos. Metacercariae of $P$. molenkampi and P. bonnei were discovered in naiads and adult dragonflies and damselflies in Thailand (Manning \& Lertprasert, 1973). Local people in northeast Thailand are known to eat naiads but not the adults of these insects (Manning \& Lertprasert, 1973). However, reservoir hosts such as monkeys are known to catch and eat both adults and naiads. In the present study, those found to be infected with $P$. molenkampi and $P$. bonnei admitted that they had eaten dragonfly naiads.

The two localities surveyed in this study were found to be endemic areas of O. viverrini, heterophyids and lecithodendriids. In Saravane, $H$. taichui was the most dominant species, whereas in Vientiane, O. viverrini predominated. These differences seem to be attributed to remarkable differences in the metacercarial infection in local fish, i.e. in fish from Saravane, the metacercariae of $H$. taichui prevailed, whereas in fish from Vientiane, those of $O$. viverrini predominated (to be published). We recommend that the small trematode eggs found in the faeces of riverside inhabitants in Laos warrant further investigation.

\section{Acknowledgements}

We are grateful to Dr Sithat Insisiengmay and the staff of the Center for Laboratory and Epidemiology, Department of Hygiene and Prevention, Ministry of Public Health, Vientiane, and staff at the Station of Malariology and Parasitology, Saravane Provincial Health Department, Saravane, Lao PDR, for their help during the collection of faecal samples from villagers and for the preparation of Kato-Katz smears. We also thank the staff of the Korea Association of Health Promotion, Seoul, Republic of Korea, who participated in the Korea-Laos Cooperation Project on Parasite Control in Lao PDR (1999-2004). This study was supported by BK21 Human Life Sciences, Ministry of Education, Republic of Korea.

\section{References}

Chai, J.Y. \& Hongvanthong, B. (1998) A small-scale survey of intestinal helminthic infections among the residents near Pakse, Laos. Korean Journal of Parasitology 36, 55-58.

Chai, J.Y. \& Lee, S.H. (2002) Food-borne intestinal trematode infections in the Republic of Korea. Parasitology International 51, 129-154.

Chai, J.Y., Murrell, K.D. \& Lymbry, A. (2005) Fishborne parasitic zoonoses: status and issues. International Journal for Parasitology (in press).

Ditrich, O., Scholtz, T. \& Giboda, M. (1990) Occurrence of some medically important flukes (Trematoda: Opisthorchiidae and Heterophyidae) in Nam Ngum water reservoir. Southeast Asian Journal of Tropical Medicine and Public Health 21, 482-488.

Ditrich, O., Giboda, M., Scholtz, T. \& Beer, S.A. (1992) Comparative morphology of eggs of the Haplorchiinae (Trematoda: Heterophyidae) and some other medically important heterophyid and opisthorchiid flukes. Folia Parasitologica 39, 123-132.

Giboda, M., Ditrich, O., Scholtz, T., Viengsay, T. \& Bouaphanh, S. (1991) Human Opisthorchis and Haplorchis infections in Laos. Transactions of the Royal Society of Tropical Medicine and Hygiene 85, 538-540.

Kaewkes, S., Elkins, D.B., Sithithaworn, P. \& Haswell-Elkins, M.R. (1991) Comparative studies on the morphology of the eggs of Opisthorchis viverrini and lecithodendriid trematodes. Southeast Asian Journal of Tropical Medicine and Public Health 22, 623-630.

Kobayashi, J., Vannachone, B., Xeutvongsa, A., Manivong, K., Ogawa, S., Sato, Y. \& Pholsena, K. (1996) Prevalence of intestinal parasitic infection among children in two villages in Lao PDR. Southeast Asian Journal of Tropical Medicine and Public Health 27, $562-565$

Kobayashi, J., Vannachone, B., Sato, Y., Manivong, K., Nambanya, S. \& Inthakone, S. (2000) An epidemiological study on Opisthorchis viverrini infection in Lao villages. Southeast Asian Journal of Tropical Medicine and Public Health 31, 128-132.

Manning, G.S. \& Lertprasert, P. (1973) Studies on the life cycle of Phaneropsolus bonnei and Prosthodendrium molenkampi in Thailand. Annals of Tropical Medicine and Parasitology 67, 361-365. 
Manning, G.S., Lertprasert, P., Watanasirmkit, K. \& Chetty, C. (1971) A description of newly discovered intestinal parasites endemic to northeastern Thailand. Journal of the Medical Association of Thailand 54, 466-474.

Pholsena, K., Sayaseng, B., Hongvanthong, B. \& Vanisaveth, V. (1991) The prevalence of helminth infection in Ban Nanin, Laos. Southeast Asian Journal of Tropical Medicine and Public Health 22, 137-138.

Radomyos, P., Bunnag, D. \& Harinasuta, T. (1984) Worms recovered in stool following praziquantel treatment. Arzneimittel-Forschung/Drug Research 34, 1215-1217.

Radomyos, P., Radomyos, B. \& Tungtrongchitr, A. (1994) Multi-infection with helminths in adults from northeast Thailand as determined by post-treatment fecal examination of adult worms. Tropical Medicine and Parasitology 45, 133-135.

Rim, H.J. (1982) Opisthorchiasis. pp. 109-121 in Steele, J.H. (Ed.) CRC handbook series in zoonoses, Section C: Parasitic zoonoses, Vol. III (trematode zoonoses). Boca Raton, Florida, CRC Press.

Rim, H.J., Chai, J.Y., Min, D.Y., Cho, S.Y., Eom, K.S., Hong, S.J., Sohn, W.M., Yong, T.S., Deodato, G., Standgaard, H., Phommasack, B., Yun, C.Y. \& Hoang, E.H. (2003) Prevalence of intestinal parasite infections on a national scale among primary schoolchildren in Laos. Parasitology Research 91, 267-272.

Segal, D.B., Humphrey, J.M., Edwards, S.J. \& Kirby, M.D. (1968) Parasites of man and domestic animals in Vietnam, Thailand, Laos, and Cambodia. Experimental Parasitology 23, 412-464.
Scholtz, T., Ditrich, O. \& Giboda, M. (1990) Larval stages of medically important flukes (Trematoda) from Vientiane Province, Laos. Part I. metacercariae. Annales de Parasitologie Humaine et Comparée 65, 238-243.

Sornmani, S., Pathammavong, O., Bunnag, T., Impand, P., Intarakhao, C. \& Thirachantra, S. (1974) An epidemiological survey of human intestinal parasites in Vientiane, Laos. Southeast Asian Journal of Tropical Medicine and Public Health 5, 541-546.

Tesana, S., Srisawangwonk, T., Kaewkes, S., Sithithaworn, P., Kanla, P. \& Arunyanart, C. (1991) Eggshell morphology of the small eggs of human trematodes in Thailand. Southeast Asian Journal of Tropical Medicine and Public Health 22, 631-636.

Yu, S.H. \& Mott, K.E. (1994) Epidemiology and morbidity of food-borne intestinal trematode infections. Tropical Diseases Bulletin 91, R125-R152.

Waikagul, J. (1991) Intestinal fluke infections in southeast Asia. Southeast Asian Journal of Tropical Medicine and Public Health 22 (Suppl.), 158-162.

World Health Organization (1995) Control of foodborne trematode infections. WHO Technical Report Series No. 849, pp. 1-157.

World Health Organization (2004) Report of Joint WHO/FAO Workshop on Food-borne trematode infections in Asia, Ha Noi, Vietnam, 26-28 November, 2002. WHO, WPRO, pp. 1-58. 